\title{
An Update on Eosinophilic Esophagitis: Etiological Factors, Coexisting Diseases, and Complications
}

\author{
Samiullah Khan ${ }^{a} \quad$ Xiaopei Guo ${ }^{b}$ Tianyu Liu ${ }^{a} \quad$ Muhammad lqbalc Kui Jiang ${ }^{\mathrm{a}}$ \\ Lanping Zhu ${ }^{\mathrm{a}}$ Xin Chen ${ }^{\mathrm{a}}$ Bang-mao Wang ${ }^{\mathrm{a}}$ \\ aDepartment of Gastroenterology and Hepatology, Tianjin Medical University General Hospital, Tianjin, China; \\ bDepartment of Gastroenterology and Hepatology, Erasmus University Medical Centre, Rotterdam, The Netherlands; \\ 'Department of Otorhinolaryngology, The First Affiliated Hospital, Sun Yat-Sen University, Guangzhou, China
}

\section{Keywords \\ Esophagus · Eosinophilic esophagitis · Etiological factors · Comorbid conditions · Complications}

\begin{abstract}
Background: Eosinophilic esophagitis (EoE) is an immunemediated clinicopathological condition characterized by esophageal infiltration with eosinophils resulting in chronic inflammation and stricture. Summary: The recent increase in the incidence of EoE and the characteristic presentation of symptoms with difficulty swallowing and food bolus impaction has raised key concerns of clinicians as well as researchers. EoE often presents with dysphagia, food impaction, nausea, regurgitation or vomiting, and decreased appetite. It is more common in males, affecting both adults and children. The causative manner of this condition is complex and multifactorial. Throughout recent years, researchers have made a significant contribution to understanding the pathogenesis of EoE, genetic background, natural history, work on allergy, and standardization in the evaluation of disease activity. There is relatively high prevalence of EoE among the population, emphasizing the importance of this disease. Key messages: Esophageal involvement with eosinophils may
\end{abstract}

be manifested as isolated or with coexisting conditions and should be taken into consideration in the differential diagnosis. This study aimed to provide gastroenterologists with novel insights into the evaluation of esophageal involvement with eosinophils and to pay special attention to the etiological factors, coexisting clinical diseases, and complications.

(c) 2020 S. Karger AG, Basel

\section{Introduction}

Eosinophilic esophagitis (EoE) is a chronic, relapsing, immune-mediated esophageal disease [1-4] characterized by hyperplasia of basal cells, microabscesses, degranulation, dilated intercellular spaces [5], and predominant eosinophilic infiltration in the esophagus [6]. The esophagus is unique from the rest of the gastrointestinal tract; normally, there is no eosinophil in the esophagus. The prevalence is higher in both children and adults [1]. In EoE, high counts of eosinophil are build up in the epithelial lining of the esophagus [7]. This eosinophilic buildup, which is a reaction to multiple factors including foods, allergens, atopic conditions, diseases, or acid reflux, may

karger@karger.com

www.karger.com/dig

(C) 2020 S. Karger AG, Base

Karger"
Prof. Bang-mao Wang

Department of Gastroenterology and Hepatology

Tianjin Medical University General Hospital

154 Anshan Road, Tianjin 300052 (China)

mwang02@tmu.edu.cn 
Fig. 1. Clinical characteristics of patients with eosinophilic esophagitis.

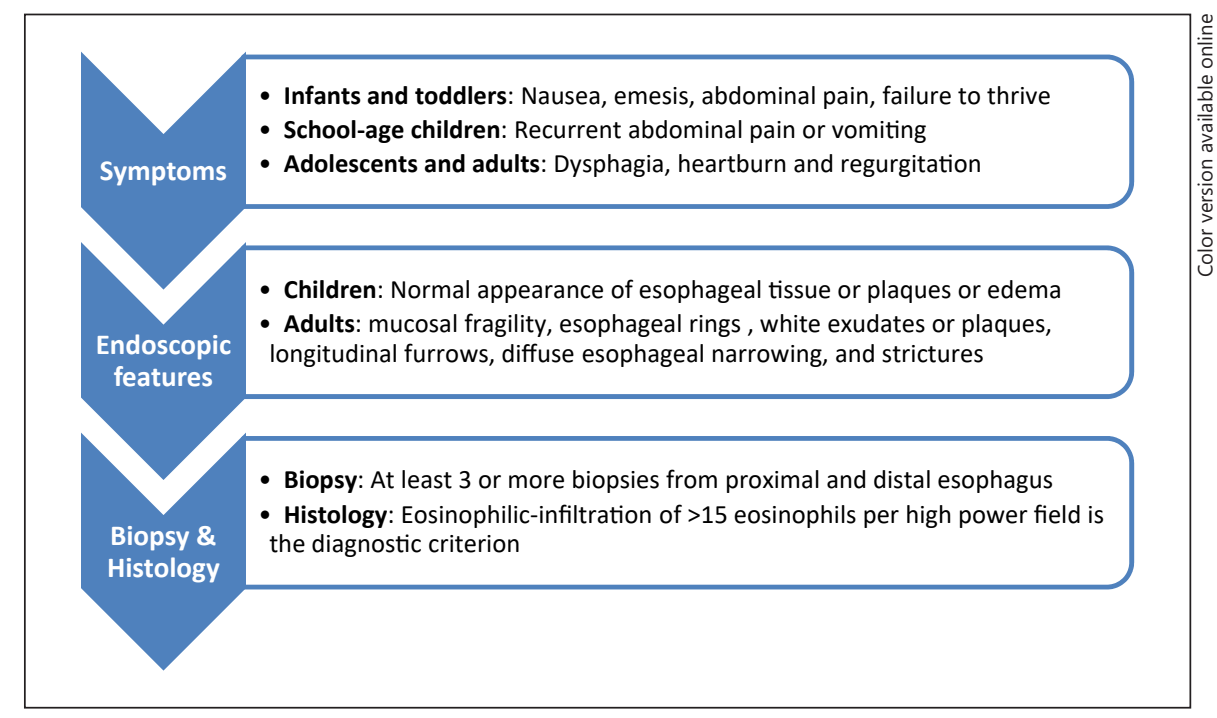

deteriorate or damage the tissue of the esophagus which contributes to fibrosis and strictures $[2,8]$.

The symptoms of patients with EoE vary with age [9]; infants and toddlers most commonly have nausea, emesis, abdominal pain, refusing eating, or not growing properly (failure to thrive) $[3,10,11]$. School-age children often experience recurrent abdominal pain or vomiting [12], and adolescents and adults have difficulty swallowing, heartburn, and regurgitation most often $[9,13,14]$ (Fig. 1).

Endoscopic characteristics of children with EoE include having either a normal appearance of esophageal tissue or plaques or edema findings, whereas adults display mucosal fragility, esophageal rings (trachealization), white exudates or plaques, longitudinal furrows, diffuse esophageal narrowing, and strictures (Fig. 2). EoE is a transmural disorder affecting all layers of the esophagus [15]. Histological identification of predominant eosinophilic infiltration of $>15$ eosinophils per high-power field (HPF) is the diagnostic criterion $[3,8,16,17]$. A minimum of 3 or more biopsies from the proximal and distal esophagus should be collected for an adequate diagnostic yield $[9,18,19]$.

\section{Epidemiological Aspects}

Over recent years, there has been a rise in the incidence and prevalence of EoE [20]. In both children and adult populations, the prevalence has also increased. It is the leading cause of dysphagia in children and young adults [20].

Etiological Factors, Coexisting Diseases, and Complications of EoE
It is estimated to be around $30-52$ cases per 100,000 inhabitants in the general population [21]. A research study between 2005 and 2011 in central Spain [22] found an average yearly incidence of $6.37 / 100,000$ residents and a prevalence of 44.6/100,000 residents, the latter being greater in urban regions [23].

EoE has been described in all races and continents and can occur at any age, and it most commonly occurs in Caucasian males [24] and has a strong hereditary component with large sibling risk ratio [11]. It is more frequent in males than in females (3:1). The mean age at the time of diagnosis ranges between 30 and 50 years in adults and 5.4 and 9.6 years in children [25].

The pathogenesis of EoE is relatively poorly understood. Increasing evidence suggests a strong involvement of genetic and environmental factors [26], premature delivery, cesarean birth, early antibiotic exposure, food allergy, lack of breast feeding, and lack of early microbial exposure are associated with EoE $[7,11]$ (Table 1).

\section{Mechanistic Aspects of Esophageal Damage in EoE}

The mechanism of dysphagia in EoE is multifactorial, including mucosal stickiness, esophageal fibrosis, strictures, and ring formation [27]. Eosinophils produce and release numerous proteins and mediators, namely, major basic protein, eosinophilic cationic protein, eosinophilderived neurotoxin, and eosinophilic peroxidase, which play a key role in tissue damage and remolding $[28,29]$. Serum analyses of absolute eosinophil count, eosinophil- 


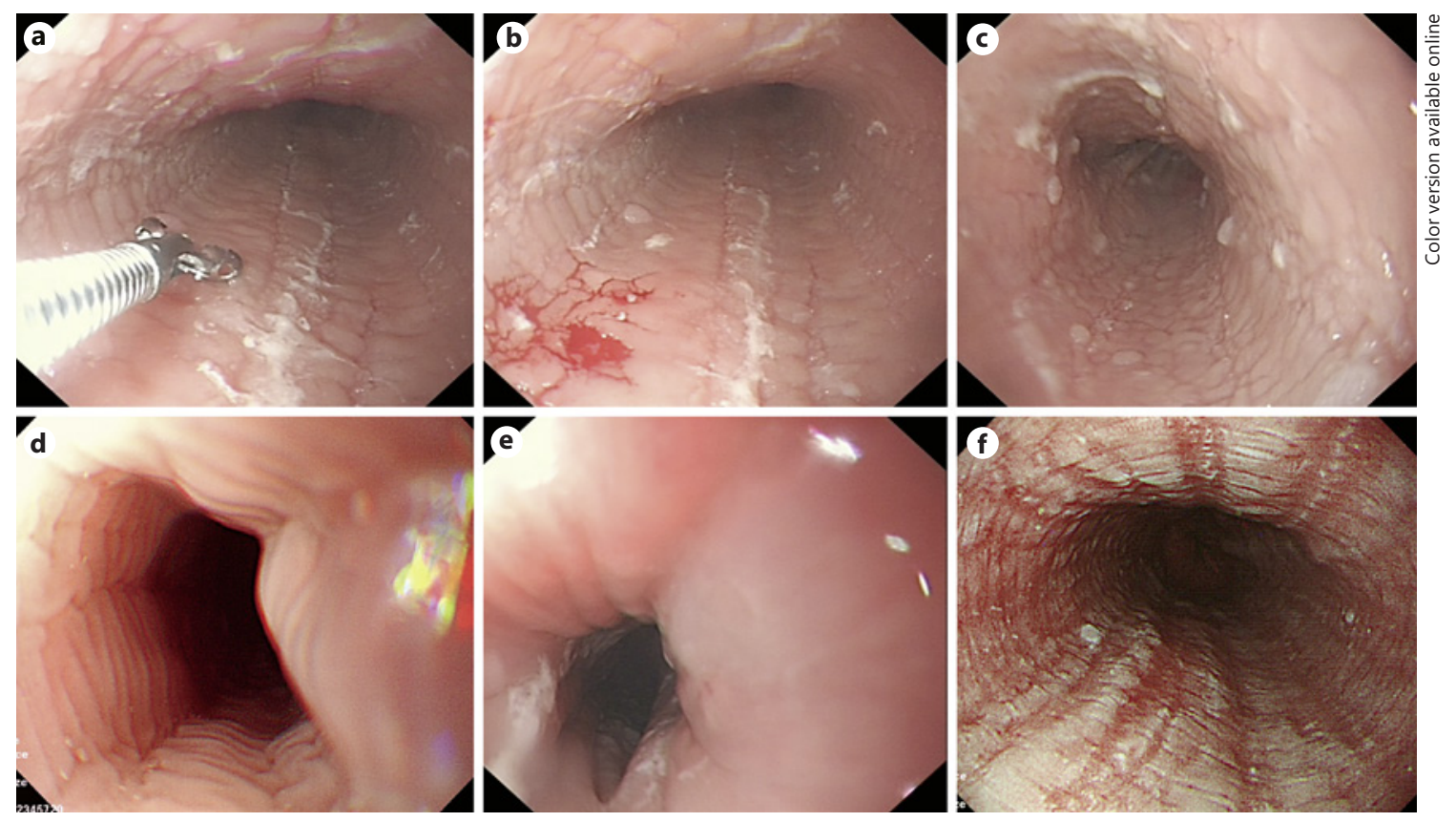

Fig. 2. Images of 3 patients (patient $1(\mathbf{a}-\mathbf{c})$; patient $2(\mathbf{d}, \mathbf{e})$; patient $3(\mathbf{f})$ ) with eosinophilic esophagitis in our endoscopic department show linear furrowing (a), mucosal friability and tearing (b), multiple nodules $0.2-0.3$ $\mathrm{cm}(\mathbf{c})$, trachealization $(\mathbf{d})$, esophageal narrowing with exudates $(\mathbf{e})$, and severe eosinophilic microabscess with linear furrowing (f).

Table 1. Epidemiology of eosinophilic esophagitis

Prevalence in both children and adults Dysphagia in children and young adults All races and continents

Any age

Commonly in Caucasian males

Hereditary/sibling risk ratio

Gender

Mean age of diagnosis in adults

Mean age of diagnosis in children

$\uparrow$
$\uparrow$
Yes
Yes
Yes
$\uparrow$
$\mathrm{M}>\mathrm{F}$
$30-50$ years
$5.4-9.6$ years

ic cationic protein, and eosinophil-derived neurotoxin were higher in EoE patients in one prospective study, besides absolute eosinophil count predicted posttreatment eosinophilia [30]. Bone morphogenetic proteins [31] promote squamous differentiation of basal progenitor cells upon their activation in the adult's esophagus, and basal cell hyperplasia in biopsy samples is associated with high levels of follistatin [32]. Activated eosinophil- and mast cell-derived transforming growth factor- $\beta 1$ secretion is crucial in EoE-associated tissue remodeling [33, 34]; also, phospholamban, an integral membrane protein,
Table 2. Mechanistic aspects of EoE

Proteins and mediators by eosinophils

Major basic protein

Eosinophilic cationic protein

Eosinophil-derived neurotoxin

Eosinophilic peroxidase

Bone morphogenetic protein

Phospholamban

Transforming growth factor- $\beta 1$

Histamine-producing mast cells and basophils

Activated $\mathrm{CD}^{+}{ }^{+} \mathrm{CD} 8^{+} \mathrm{T}$ cells

Tumor necrosis factor- $\alpha$

Interferon gamma

EoE, eosinophilic esophagitis.

is an important player in transforming growth factor- $\beta 1$ mediated esophageal squamous mucosa cell and myofibroblast contraction in the pediatric population [35].

Eosinophils and mast cells $[36,37]$ as well as histamineproducing mast cells and basophils [38-40] play a very important role in bringing eosinophils into the esophageal 
Table 3. Etiological factors associated with EoE

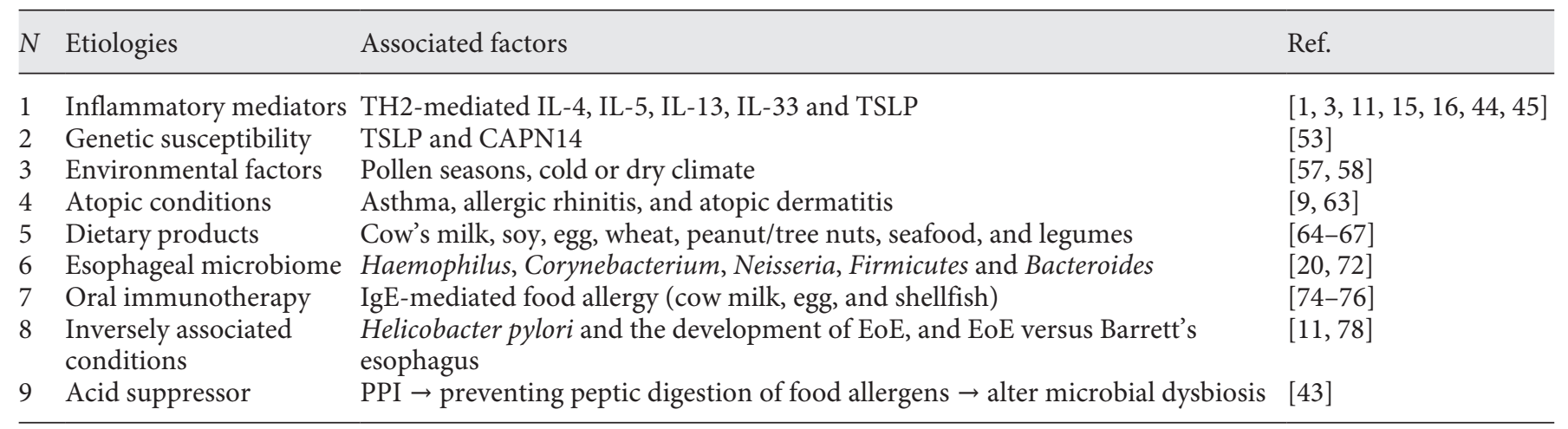

EoE, eosinophilic esophagitis; TH2, T helper type 2; IL, interleukin; TSLP, thymic stromal lymphopoietin; CAPN14, calpain 14; IgE, immunoglobulin E; PPI, proton pump inhibitors.

epithelium [39]. In the EoE-active group, a high number of activated $\mathrm{CD}^{+}{ }^{+} \mathrm{CD} 8^{+} \mathrm{T}$ cells were found to secrete tumor necrosis factor- $\alpha$ and interferon gamma in comparison with the EoE-remission and control groups [18]. Moreover, the role of calcium-activated chloride channel Anoctamin 1 in esophageal cell proliferation and basal zone hyperplasia in EoE has also been reported (Table 2).

\section{Etiological Factors}

Certain conditions such as inflammatory mediators, genetic susceptibility, environmental factors, atopic conditions, dietary products, esophageal microbiome, and oral immunotherapy have been associated with a higher risk of EoE formation. However, various other conditions with distinct clinical and histological characteristics have also been identified to be associated with esophageal eosinophilia such as eosinophilic gastrointestinal diseases, proton pump inhibitor (PPI)-responsive esophageal eosinophilia, drug hypersensitivity, pemphigus, connective tissue disorders, graft-versus-host disease [41], and hypereosinophilic syndrome, a rare group of conditions that are associated with persistent high eosinophilia with eosinophil counts $>1,500 / \mu \mathrm{L}$, which most commonly affects the heart, central nervous system, skin, and respiratory tract [42].

Moreover, there is a hypothesis that medications such as acid suppressor (PPIs) might contribute to the pathogenesis of EoE by preventing peptic digestion of food allergens and altering microbial dysbiosis. EoE such as eosinophilic gastroenteritis might have mucosal and muscle predominant types that may cause esophageal motility disorders including achalasia [43] (Table 3).

\section{Inflammatory Mediators}

EoE is still a relatively poorly understood entity. Increasing evidence indicates a vigorous presence of the involvement of genetic and environmental factors [26]. The Thelper type 2 (TH2)-mediated inflammatory cytokines, interleukin (IL)-4, IL-5, IL-13 [1, 3, 11, 15, 16, 44, 45], and IL-33 in pediatric [46], and invariant natural killer T cells [26] are involved in trafficking eosinophils into esophageal tissue.

Activation of signal transducer and activator of transcription-6 (STAT6) by IL-4 and IL-13 mediates the pathogenesis of allergic disorders $[47,48]$. In experimental models, IL-13 has been demonstrated to induce esophageal eosinophilia and regulate numerous identified genes associated with EoE [11]. Moreover, epithelial cells and the thymic stromal lymphopoietin (TSLP) gene and its receptor appear to be risk factors for EoE as they undergo polymorphisms in the eotaxin-3 [49-51] and other chemoattractants [15].

\section{Genetic Susceptibility}

Genetic associations are prone to various types of allergic conditions, including EoE. The TSLP and calpain-14 (CAPN14) are 2 widely studied genetic components involved in EoE and atopy. Variants in the 5q22 locus encoding the gene for TSLP have been associated with EoE and the most common atopic diseases, including atopic dermatitis, asthma, and allergic rhinitis [20, 52]. TSLP is an epithelial cell-derived cytokine that is secreted in response to allergen exposure on membrane surfaces and is involved in the initiation of type 2 inflammation. 
In the esophagus, TSLP in biopsy samples from subjects with EoE was found to be overexpressed as compared with healthy individuals [52]. Similarly, variants in the 2 p33 locus encoding the CAPN14 gene are strongly associated with EoE and atopy, with CAPN14 upregulation in the esophagus among those with active esophagitis or after exposure to type 2 cytokines [53]. Previous reports have also found the association of CAPN14 dysregulation with epithelial barrier dysfunction [54]. Likewise, these studies show a common set of genetic changes that may predispose an individual to various allergic manifestations, including EoE.

\section{Environmental Factors}

The rapid change in incidence and prevalence of EoE demonstrates the potential importance of environmental factors $[11,55]$. Environmental allergen exposure may also play critical roles in the pathogenesis and ongoing manifestations of EoE, such as pollen seasons spring/fall or living in a cold or dry climate [11]. About the temperate climate zone, studies reported an increased risk of EoE in patients residing in a cold climate zone [56]. While some of these studies suggest an association between season and EoE [57, 58], some studies have indicated no association $[59,60]$.

Recently, a study related to seasonality and pollen counts was carried out in $36 \mathrm{EoE}$ patients in the New York City area. The counts of 11 different pollen taxa were studied, including Acer (maple), Betula (birch), Populus (poplar), Ulmus (elm), Quercus (oak), Carya (hickory), Fraxinus (ash), Platanus (sycamore, London planetree), Fagus (beech), Poaceae (grass pollen family), and Ambrosia (ragweed). Increased patient symptoms were recorded in summer, and increased diagnoses were noted in the fall months. Moreover, symptoms of EoE correlated with peak levels of grass pollen [61]. Similarly, another study showed differences in the association between seasonality and EoE by climate zone, with the strongest evidence of seasonal variation in EoE diagnoses in temperate and cold climates. Higher EoE diagnosis was associated with summer months, but peak diagnoses varied by month depending on the climate zone [55].

Besides, peripheral eosinophilia and elevated serum immunoglobulin E (IgE) levels are usually found in 50 and $75 \%$ of patients [13], and there is no phenotypical variation in adult EoE with IgE-mediated food sensitivity and non-food-sensitive patients [62]. Together, these results point toward climate and geographic changes, suggesting that aeroallergens may contribute to the development of disease or flare.

\section{Atopic Conditions}

The majority of patients with EoE are atopic [2, 26, 44]. Most studies reported associations between EoE and atopic disorders. Patients with EoE are at increased risk of asthma, allergic rhinitis, atopic dermatitis, and food allergies, suggesting potential common pathogenesis $[25$, 63].

In general, eosinophils have been hypothesized to move to the esophagus in response to various ingested and/or inhaled allergens, thereby associating EoE with allergy-induced diseases. As a result of that, a high prevalence of atopic diseases (e.g., asthma, allergic rhinitis, and atopic dermatitis) and sensitization to food and environment allergens is seen in pediatric and adult EoE populations $[9,64]$.

\section{The Role of Dietary Products in EoE}

In the pathophysiology of EoE, food allergy is believed to play a crucial role [65-68]. However, the relationship between food allergy and EoE is complex. Allergy tests (skin tests, patch tests, or blood tests) are important. Many studies have shown that most EoE patients have evidence of IgE-mediated food sensitization based on IgE-specific in vitro or skin prick testing [64]. Once a food is eliminated from the diet of a patient, symptoms usually improve in a couple of weeks.

Foods such as dairy products, egg, soy, and wheat can cause an allergic disorder that is non-IgE mediated [44] and are the main causes of EoE. Wheat and cow's milk are a commonly implicated trigger in EoE. Exclusive cow's milk evading has recently been documented, and cow's milk elimination induced clinicopathological remission in most EoE patients, endorsing its use as a first-line intervention. However, a 6-food elimination diet targeting the common intact proteins is associated with food allergies (cow's milk, soy, egg, wheat, peanut/tree nuts, and seafood).

The recurrence of esophageal eosinophilia after the reintroduction of food provides definite evidence of the role of food allergens in EoE [69]. A more tolerable 4- food elimination diet (dairy products, wheat, egg, and legumes) was followed by adult EoE patients; after sequential reintroduction of food(s), only 1 or 2 foods were reported as responsible for EoE in $65-85 \%$ of all EoE patients, regardless of age [68]. This approach has the benefit of shortening the time it takes to identify the food(s) responsible for EoE, meaning fewer endoscopic procedures. 
The Role of Esophageal Microbiome in EoE

The human microbiome is both immense and complex, with 100 trillion microbes representing multiple genera colonizing the gastrointestinal tract alone [70]. Recently, the microbiome has been concerned with various allergic and inflammatory diseases. The esophagus is colonized by hundreds of bacterial species, with members of the Firmicutes and Bacteroides phyla being among the highest in both children and adults [20].

The esophageal microbiome may play a vital role in EoE, especially Haemophilus[71, 72], Corynebacterium, and Neisseria [20,73]. According to the study by Harris et al. [71], the average bacterial load detected in all subjects with EoE was significantly greater than that determined from normal subjects. By comparison, there was also a significant increase in the average bacterial load observed in gastroesophageal reflux disease (GERD) subjects compared with normal esophagus control subjects.

Besides, alterations in the salivary microbiome have also been reported in EoE [72]. The associations between early-life environmental pressures and the development of EoE existed. For example, antibiotic exposure and diet known to influence and alter normal esophageal flora are associated with EoE in the majority of studies. Similarly, cesarean delivery also increases the risk of EoE. Such findings together support the role of environmental pressures that modify the microbiome, leading to the development of EoE and other allergic manifestations. To expand upon this work and identify the most relevant microbes and involvement of immunological mechanisms, however, future research is necessary.

\section{Oral Immunotherapy and EoE}

Recently, the increasing number of EoE detection in patients undergoing oral immunotherapy (OIT) for IgEmediated food allergy has raised serious concerns that OIT may elicit EoE in susceptible individuals. This association was further investigated in a meta-analysis showing a positive correlation between OIT and EoE, with the occurrence of new onset in $2.7 \%$ of OIT patients [20,74]. However, it is uncertain at present whether OIT triggers EoE or whether OIT aggravates moderate EoE in otherwise subclinical individuals.

The prevalence of EoE was observed higher in patients with IgE-mediated food allergy than in the general population [75], and the history of IgE-mediated food allergy to the 3 common food allergens (milk, egg, and shellfish) was closely linked to the subsequent diagnosis of EoE [75]. Gómez Torrijos et al. [76] reported 57 children who underwent OIT for cow milk allergy in which 3 of them were diagnosed with EoE and asymptomatic esophageal eosinophilia after a cow milk-free diet. Moreover, the author also stated that all patients allergic to cow milk who underwent OIT developed EoE, showed unfavorable progress, and required a dose reduction of cow milk.

In one follow-up study, a hazardous ratio of 9.1 for children with IgE-mediated food allergy in developing EoE was observed, the strongest association was detected among the various allergic march relationships [77]. Such findings together indicate that both IgE-mediated food allergy and EoE may result from a common allergen-specific TH2 response. Furthermore, the concern for iatrogenic EoE in patients undergoing OIT is warranted, and patients undergoing OIT should be strictly monitored for EoE symptoms.

\section{Inverse Relationship between EoE and Helicobacter pylori}

An interesting inverse association between EoE and $H$. pylori[11] and an inverse relationship between $H$. pylori and the development of EoE were established in recent studies taking into account that environmental factors might influence the development of EoE [56, 78]. Furthermore, $H$. pylori infection has been found to be inversely related with atopic diseases (asthma, atopic dermatitis, and allergic rhinoconjunctivitis) and may play a protective role in these conditions [63]. Similarly, an inverse relationship between EoE and Barrett's esophagus has also been reported in a Japanese study [79]. A study by Dellon et al. [80] reported an inverse relationship of esophageal eosinophilia and $H$. pylori infection (OR 0.77) in esophageal biopsy samples accumulated from a US pathology database. Also, the analysis showed that odds of H. pylori infection decreased as esophageal eosinophilia increased (OR 0.52 for $>90$ eosinophils/HPF).

Moreover, von Arnim et al. [63] reported serological analyses for $H$. pylori infection in 58 patients with clinically and histologically proven EoE. Among them, 3 patients reported with current $H$. pylori infection and 5 patients reported with previous eradication therapy for $H$. pylori infection as serologically negative posteradication therapy status. EoE patients with current $H$. pylori infections displayed a significantly lower prevalence than the control groups. EoE (current and former) was strongly inversely associated with seroprevalence of $H$. pylori (OR $0.24,95 \%)$.

Recently, a large multicenter case-control study straightly examined the relationship between $H$. pylori and EoE in a prospective manner. A total of 808 individuals, including 170 children, were studied. The study 
found no difference in $H$. pylori prevalence between cases and control groups in either children or adults [81]. A possible correlation between EoE and H. pylori infection has not been sufficiently investigated in the literature and therefore requires further study and discussion.

\section{Comorbid Conditions}

EoE is a chronic, allergic, immune system-mediated disease associated with an increased risk of comorbid conditions (Table 4).

\section{Possible Relationships between GERD and EoE}

Over the past 2 decades, esophageal eosinophilia has progressed from a clinical criterion of GERD to an ultimate histological marker of EoE and now back to an actually complex association between the 2 entities. The increasing GERD reports in the general population are high enough to make the coexistence of GERD with EoE inevitable. EoE and GERD have overlapping clinical, endoscopic, manometric, and histopathologic features. EoE may contribute to the development of GERD via many eosinophil products that can relax the muscle of the lower esophageal sphincter as a result altering motility or causing structural changes. In contrast, GERD causes EoE, leading to acid injury of the epithelium, increased epithelial permeability, and increased immune cells recruitment $[26,67,82]$.

EoE is commonly seen in dysphagic patients and, to a lesser extent, PPI-resistant GERD [64]. According to the study by Zukerberg et al. [83], patients with EoE (mean peak eosinophil count of 53/HPF) showed increasingly higher intraepithelial eosinophilic numbers than those with reflux esophagitis (mean peak eosinophil count of 27/HPF).

In general, patients with EoE demonstrate diffuse esophageal involvement (as measured by the number of eosinophils), while reflux esophagitis is usually confined to the distal part of the esophagus. Moreover, the study stated that patients with EoE showed significant submucosal fibrosis and abscesses which composed of eosinophils.

The literature by García-Rojo et al. [40] reported that CD3-, CD4-, and CD8- marker analysis may be used to distinguish between GERD and EoE patients. In rare situations, for example, children with strong clinical suspicion where fragments do not reach 15 intraepithelial eosinophils/HPF, immunostaining for arachidonate-15 lipooxygenase has been found to be a sensitive marker for
Table 4. Coexisting conditions with EoE

\section{GERD}

IBD (Crohn's disease and ulcerative colitis)

$\mathrm{CD}$

Lymphocytic esophagitis

Eosinophilic cholangitis

Type $2 \mathrm{~B}$ von Willebrand disease

Esophageal intramural pseudo diverticulosis

Vascular changes in eosinophilic esophagitis

Immunoglobulin G4-related disease

Herpetic esophagitis

Esophagitis dissecans

Siderius-Hamel syndrome

EoE and eosinophilic subserosal gastroenteritis with ascites

EoE, eosinophilic esophagitis; GERD, gastroesophageal reflux disease; $C D$, celiac disease; IBD, inflammatory bowel disease.

EoE [84]. Moreover, von Arnim et al. [85] reported 10 characteristic marker set (atopy, food impaction, dysphagia, PPI-refractory symptoms, peripheral eosinophilia, IgE, weight loss, painful swallowing/odynophagia, age, and sex) which effectively distinguish GERD from EoE. Besides, the 10 markers were further reduced to 4 parameters (history of atopy, history of food impaction, PPIrefractory symptoms, and either IgE or peripheral eosinophilia), which were also able to excellently predict EoE and differentiate EoE from GERD.

In refractory GERD patients, EoE is not uncommon. It may exist with symptoms of dysphagia, heartburn, and the impaction of food. Esophageal screening with biopsy is necessary for older patients with longstanding GERD, positive for atopy, or not responding to gastric acid inhibitors.

\section{EoE and Inflammatory Bowel Disease}

Inflammatory bowel disease (IBD) and EoE are chronic inflammatory disorders associated with an impaired mucosal immune response; however, the immune responses are different. EoE is believed to be an antigendriven allergic disorder in genetically predisposed individuals mediated by $\mathrm{TH} 2$ cells, which contributes to eosinophil migration into the esophageal mucosa. In contrast, IBD is regarded as multifactorial. More recently, the coexistence of EoE and IBD has been increasingly recognized [66, 86, 87]. Talathi et al. [86] reported a case series of 6 pediatric patients with coexisting EoE and IBD (4 Crohn's disease and 2 ulcerative colitis), which revealed characteristic endoscopic and histological findings suggestive of EoE. 
Regarding the gastrointestinal tract, eosinophilia is common in IBD and the number of eosinophils is reliant on the severity of the disease. Recent studies reported a progressively complex course in patients with concurrent IBD and EoE, which includes IBD-related complications, poor response to infliximab, and poorer nutritional outcomes [87].

This study underlines the need for physicians to consider the possibility of concurrent EoE and IBD, particularly when the eosinophilic condition is isolated to the esophagus in patients with IBD and the existence of other histological features related EoE. Such understanding will help in the early diagnosis and management of these patients and also help to better understand the relationship between these 2 conditions.

\section{EoE and Celiac Disease}

Celiac disease (CD) and EoE have recently been the main focus of various pediatric studies with variable outcomes. Both diseases are mediated by the immune system, and dietary factors play a significant role in their pathogenesis. When untreated, both diseases lead to the destruction of the epithelium [88]. Both celiac disease and EoE need biopsy results for diagnosis, and both conditions may occur despite an utterly normal appearance of the mucosa [89].

One study reported the initial endoscopic evaluation of 10 children with coexisting $\mathrm{CD}$ and EoE on histopathological findings; their symptoms improved after a gluten-free diet, topical glucocorticosteroid, and elimination diet [88]. Patton et al. [90] reported a cohort of 22 patients diagnosed with CD and EoE, in whom soy was well tolerated, and suggested that reintroduction of this food first, or trialing a soy-inclusive dietary elimination is a viable strategy. Moreover, Vaz et al. [91] reported a patient with characteristic features of EoE and underwent topical and systemic corticosteroids, in whom repeated endoscopy of the duodenal mucosa showed multiple papules and the biopsies' results were consistent with CD. Furthermore, Ari et al. [92] evaluated both isolated CD and EoE and combined CD + EoE and stated that these are 2 coexisting entities in patients who present with combined CD $+\mathrm{EoE}$ and they share certain characteristics with their counterparts with isolated $\mathrm{CD}$ and EoE.

According to Wallach et al. [89], there is greater adherence to guidelines for biopsy in which celiac disease and EoE are ultimately diagnosed. The diagnoses of both CD and $\mathrm{EoE}$ are associated with adequate adherence to the guidelines, and detection rates of the disease increase with increased mucosal sampling.

Etiological Factors, Coexisting Diseases, and Complications of EoE

\section{EoE and Lymphocytic Esophagitis}

Lymphocytic esophagitis most commonly present with symptoms of dysphagia, abdominal pain, heartburn, and nausea. Endoscopic features of lymphocytic esophagitis can be similar to EoE including esophageal rings, furrows, exudates, narrow lumen, or stenosis, but in onethird of patients, the esophageal mucosa appears macroscopically normal [93].

Lymphocytic esophagitis is diagnosed when more than 40 intraepithelial lymphocytes/HPF are present and no intraepithelial granulocytes or occasional presence of CD15 + intraepithelial granulocytes. The compound eosinophilic and lymphocytic esophagitis can be considered in patients who fulfilled both EoE and lymphocytic esophagitis diagnostic criteria ( $>15$ eosinophils/HPF and $>40$ intraepithelial lymphocytes/HPF) [93, 94].

EoE and lymphocytic esophagitis can sometimes be considered as an overlapping phenotype of endoscopic features similar to that in EoE when there are over 40 intraepithelial lymphocytes/HPF present $[93,94]$. According to the study by Truskaite et al. [93], compound EoE/ lymphocytic esophagitis show the leading cause of food bolus impaction in patients $<50$ years of age.

\section{Relationship between EoE and Eosinophilic Cholangitis}

Eosinophilic cholangitis is a rare condition defined as an eosinophilic infiltration of the biliary tree that can lead to fibrosis, stricture, and biliary obstruction. Recently, Tanaka et al. [95] reported a 70-year-old female with eosinophilic cholangitis with a past history of EoE, who was treated with prednisolone $(2.5-7.5 \mathrm{mg} /$ day $)$ for 1 year. She was negative for the hepatitis virus and IgG4 staining. However, marked eosinophilic infiltrates were seen on her biliary biopsy in the common bile duct ( 60 cells/HPF). She was started with prednisolone $30 \mathrm{mg} /$ day and tapered the dose to $2.5 \mathrm{mg} /$ day, and she was asymptomatic without common bile duct wall thickening.

\section{EoE and Type $2 B$ von Willebrand Disease}

von Willebrand disease is the most common hereditary blood-clotting disorder in humans. There are 4 hereditary types: type 1 , type 2 , type 3 , and pseudo or platelet-type. Type 2 is subdivided into 4 types: $2 \mathrm{~A}, 2 \mathrm{~B}, 2 \mathrm{M}$, and $2 \mathrm{~N}$.

A case study by Corder et al. [96] reported a 20-yearold female with type $2 \mathrm{~B}$ von Willebrand disease with an 8 -year history of solid food dysphagia. Type $2 \mathrm{~B}$ von Willebrand condition is characterized by qualitative defects in the "von Willebrand factor" structure or function. She 
had a history of bleeding ranging from recurrent epistaxis, easy bruising, gum bleeding, prolonged menses, and 2 severe episodes of hemoperitoneum secondary to a ruptured ovarian cyst requiring hospitalization. Her initial endoscopy revealed longitudinal furrows, white plaques, and edema throughout the esophagus with a severe focal stricture at the gastroesophageal junction. Esophageal biopsies revealed increased eosinophils in both the proximal (60 eosinophils/HPF) and distal esophagus (80 eosinophils/HPF). She underwent multiple balloon dilation 13.5-18 mm with preprocedure and postprocedure prophylaxis of human plasma-derived von Willebrand factor (HP-vWF-FVIII) concentrate prophylaxis.

\section{Esophageal Intramural Pseudodiverticulosis}

It is a rare idiopathic benign condition characterized by a flask-like outpouching of the esophageal wall that is distinguished by dilatation and inflammation of excretory ducts within submucosal glands of the esophagus. Patients with EoE and pseudodiverticulosis had significantly more food bolus obstructions.

Few cases have been reported on concomitant EoE with pseudodiverticulosis. Scaffidi et al. [97] documented 5 patients with pseudodiverticulosis who had endoscopic findings suggestive of EoE and met the histological criteria of $\geq 15$ eosinophils/HPF.

Patients with EoE tend to have pseudodiverticulosis within the mid-to-distal esophagus, whereas patients without EoE had pseudodiverticula primarily in the proximal esophagus. Moreover, Kathi et al. [98] reported an endoscopic and biopsy findings of a patient with dysphagia and gastroesophageal reflux disease who was found to have an esophageal pseudodiverticula along with EoE.

\section{Vascular Changes in EoE}

The changes in the vascular structure and function and their association in hypertension can sometimes severely damage blood vessels, which can lead to a significant narrowing of blood vessels and ischemia in various tissues. Mahjoub et al. [99] reported an esophageal biopsy of a pediatric patient with EoE overlying small arteries within the lamina propria showed markedly thickened media with medial hypertrophy to the point of obstruction.

Moreover, Frech et al. [100] reported EoE patients with diffuse cutaneous systemic sclerosis, Raynaud's, and skin thickening, one had facial telangiectasia and another had early interstitial lung disease. The gastrointestinal tract, especially the esophagus, is most commonly affected by systemic sclerosis.

\section{Immunoglobulin G4-Related Disease}

The role of immunoglobulin G4 (IgG4) in the development of EoE is unclear. There are predominant IgG4-associated plasma cells up to 180-300/HPF in the deep lamina propria in adult EoE, not an IgE-induced allergy [101-103].

According to the study by Clayton et al. [101], esophageal deposits of IgG4 in EoE arise from dense plasmacytic infiltrates in the lamina propria, which shows abundant IgG4-containing plasmacytes, and IgG4 serum levels reactive to particular foods, indicating that EoE in adults is IgG4-associated. Moreover, Zukerberg reported 58 and $40 \%$ of cases with EoE and GERD that were positive for mucosal IgG4 plasmacytes, indicating that the presence of intrasquamous IgG4 deposits is a useful adjunctive marker in differentiation between GERD and EoE patients [83, 104, 105].

These findings indicate the possible associations between EoE and IgG4-related diseases. However, fibrosis is a characteristic feature of both IgG4-related disease and EoE, although the quality and the pattern of fibrosis are generally different: IgG4-related disease is characterized by fibrosis of the storiform type, whereas EoE has a pattern-less fibrosis pattern $[2,104]$.

\section{Herpetic Esophagitis with EoE}

Herpes simplex esophagitis is an acute and severe viral infection of the esophagus, rarely seen in individuals with immunocompetence. Various studies indicated a possible link between herpes simplex virus infection/esophagitis and EoE [11].

Both entities can be diagnosed simultaneously or one prior to the other, raising a possible causal relationship $[106,107]$. A study by Fritz et al. [106] retrospectively evaluated 5 immunosuppressed and 11 immunocompetent herpetic esophagitis patients' data. After herpes simplex infection, the 5 immunosuppressed patients had repeated biopsies, which revealed eosinophilic infiltration in accordance with current EoE diagnostic criteria. However, EoE was a comorbid in almost half of the $11 \mathrm{immu-}$ nocompetent patients. Similarly, a series of 5 adult patients with herpes simplex esophagitis had histological and clinical symptoms consistent with the diagnosis of EoE [108]. Kim et al. [109] reported an 11-year-old Korean boy suffering from fever, odynophagia, dysphagia, and chest pain. His upper endoscopic examination of the distal esophagus revealed longitudinal ulcers with volcanic appearance. The test results for a polymerase chain reaction and biopsy samples were found positive for herpes simplex virus type 1 . He received acyclovir and PPIs, 
Table 5. Complications associated with EoE

\begin{tabular}{ll}
\hline Conditions & Characteristics \\
\hline Inflammatory conditions & Furrows, white exudates, edema, esophageal rings, and stenosis \\
\hline $\begin{array}{l}\text { Esophageal perforation } \\
\text { Hepatic portal venous gas }\end{array}$ & $\begin{array}{l}\text { Intraluminal gas enters the portal venous circulation due to endoscopic dilation for benign esophageal } \\
\text { strictures with EoE }\end{array}$ \\
\hline $\begin{array}{l}\text { Intramucosal dissection of } \\
\text { the esophagus }\end{array}$ & $\begin{array}{l}\text { Inflammatory conditions } \rightarrow \text { separation of mucosa and/or submucosa } \rightarrow \text { false lumen } \\
\text { Esophageal dysmotility }\end{array}$ \\
$\begin{array}{ll}\text { Esophageal mucosa infiltration by eosinophils and their interactions with the microenvironment and } \\
\text { inflammatory cytokines }\end{array}$ \\
\hline Achalasia-like changes & $\begin{array}{l}\text { Esophageal muscularis propria } \rightarrow \text { abnormally buildup of eosinophils } \rightarrow \text { myoactive and neuroactive } \\
\text { eosinophilic secretory products } \rightarrow \text { cytotoxic eosinophil secretory products }\end{array}$ \\
\hline Adrenal insufficiency & Low morning serum cortisol levels \\
\hline EoE, eosinophilic esophagitis.
\end{tabular}

but the follow-up esophagoscopy demonstrated typical EoE patterns and the biopsies were consistent with the EoE diagnostic criteria. For immunocompetent patients with herpetic esophagitis, especially those with atopic conditions, clinical follow-up is therefore required.

\section{Esophagitis Dissecans with EoE}

Esophagitis dissecans superficialis and EoE are distinctive esophageal conditions with characteristic clinical and histological findings. Esophagitis dissecans superficialis is an unusual endoscopic finding consisting of peeling large esophageal mucosa fragments. Esophagitis dissecans patients may vomit casts of sloughed-off esophageal mucosa, while others may present with dysphagia, epigastric pain, or heartburn.

Guerra et al. [110] reported a patient with both esophagitis dissecans and EoE with significant mid-esophageal findings of gross abnormality of ulcerations, furrowing, streaks of white layering of mucosa with sloughing, and friability. Severe esophagitis was observed on histology with marked squamous epithelium infiltration of neutrophils and eosinophils and mucosal separation with bullous spaces and ulceration. These findings together signify that esophagitis dissecans might be another unspecific finding of EoE and the differential should be considered while encountering such conditions.

\section{Siderius-Hamel Syndrome}

It is characterized by intellectual disability and distinct facial features. Recently, a triple association of (Crohn's disease, celiac disease, and EoE) was reported in a child with Siderius-Hamel syndrome [111]. Thus, physicians should be aware of this rare occurrence while evaluating patients with Siderius-Hamel syndrome.

\section{Eosinophilic Subserosal Gastroenteritis with Ascites}

A recent study of a 30-year-old woman with increased peripheral eosinophilia, IgE, and tumor marker Ca-125 revealed increased thickening of the esophageal and small bowel wall with ascites as well as marginally narrowed esophageal lumen with eosinophils $>15 / \mathrm{HPF}$ [112].

\section{Complications}

EoE is a prolonged esophageal inflammatory condition with persistent or spontaneous course of instability. So far, life expectancy does not seem to be affected, but it often affects the quality of life. To date, no association between esophageal cancer and EoE was found [113]; however, there are major concerns that the prolonged, uncontrolled inflammation may cause irreversible structural changes in the esophagus, resulting in tissue fibrosis, stricture formation, and impairment of the esophageal function (Table 5).

\section{Inflammatory Conditions}

EoE may present with an inflammatory phenotype, such as furrows, white exudates, and edema, or stricturing phenotype (rings and stenosis) [14], or a combination 
of them. In this regard, partial or complete esophageal obstruction due to esophageal scarring and narrowing or food impaction and eating difficulties are 2 important complications of EoE and is a medical emergency [93].

\section{Esophageal Perforation}

Perforation of the esophagus is a potentially serious complication of EoE. To date, a few cases of spontaneous esophageal perforation have been reported in patients with EoE, also known as Boerhaave syndrome. The presence of eosinophilic infiltrates is the possible mechanism that causes epithelial inflammation to progress toward fibrostenotic condition that leads to esophageal remodeling. This remodeling potentially deteriorates esophageal motility and often leads to dysphagia and food impaction, and spontaneous perforation may occur as damage progress [114-116]. Moreover, Gisasola et al. [4] reported a patient with mediastinal abscess secondary to EoE without trauma, perforation, or previous surgery.

It is important to note that vomiting-induced esophageal perforation is a potentially serious complication of EoE. Therefore, EoE should be evaluated in patients with nontraumatic Boerhaave syndrome, especially young men with a prior history of dysphagia and allergies.

Endoscopic interventions for alleviating food impaction may result in complications such as esophageal perforation due to the friability of the esophageal mucosa [116]. Because of chronic inflammation of the esophagus, endoscopy can cause instrumental perforation, vertical mucosal lacerations, and emesis-induced rupture or tears in the esophageal lining tissue upon esophageal dilatation. Sometimes, tearing happens spontaneously. In rare cases, spontaneous transmural esophageal perforation has also been noted $[14,114]$.

\section{Esophageal Dysmotility}

In older children and adults, intermittent dysphagia and food impactions are the 2 most common symptoms of EoE. However, in most cases, there is no underlying anatomical condition, which could lead to major esophageal motility disorders [117, 118].

The etiopathogenesis is not well known for esophageal dysmotility. It may be associated with esophageal mucosa infiltration by eosinophils and its interactions with the microenvironment. It is unclear how eosinophilic infiltration might produce esophageal dysmotility; however, many speculations exist that the interaction of fibroblasts with eosinophils, eosinophil degranulation, binding of the eosinophil-derived major basic protein with muscarinic acetylcholine receptors, gastric eosinophilia, and in- flammatory cytokines might be the leading causes of esophageal dysmotility [117].

According to Martin Martin et al. [118], pan-esophageal pressurization is associated with bolus impaction in patients with EoE. Moreover, pan-esophageal pressurization has been found to be the most common esophageal motor abnormality assessed by high-resolution manometry.

\section{Achalasia-Like Changes}

Achalasia is an impaired peristaltic condition of the esophagus due to neuronal damage in myenteric plexus resulting in incomplete relaxation of the lower esophageal sphincter. However, achalasia is rarely associated with EoE, the majority of patients with achalasia have evidence of an abnormal buildup of eosinophils and/or their degranulation products in the esophageal muscularis propria.

Esophageal eosinophilia may cause achalasia-like motility defects, likely by releasing myoactive and neuroactive eosinophilic secretory products, which disrupt peristalsis and interfere with lower esophageal sphincter relaxation, and by releasing profibrotic products causing tissue remodeling. Moreover, achalasia can also be caused by esophageal eosinophils by releasing cytotoxic eosinophil secretory products that destroy intramural neurons of the esophagus, which mediate peristalsis and lower esophageal sphincter relaxation. Hypothetically, it is unclear whether the destruction of enteric neurons in achalasia is the cause of eosinophils infiltrating the esophageal muscular propria, nor clear that an antigen-driven EoE mainly involves the esophagus muscle, contributing to the development of abnormal esophageal motility [17, 119]. A study by Surdea-Blaga et al. [17] reported a patient with EoE who underwent a high-resolution esophageal manometry and upper gastrointestinal endoscopy for dysphagia and food impaction which revealed achalasia-like pattern, multiple white spots, along the entire esophagus with 39 eosinophils/HPF, eosinophilic microabscesses, and basal zone hyperplasia. He was started on prednisone $25 \mathrm{mg}$ /day, tapered to $5 \mathrm{mg} /$ week. His symptoms relieved during the treatment; however, after stopping the steroids, the dysphagia reappeared. Similarly, Landres et al. [120] reported EoE in a patient with vigorous achalasia presented with epigastric pain, eosinophilic infiltration of the esophagus, and esophageal hypertrophy with predominant muscle layer involvement [120]. Further research is needed to investigate the role of eosinophils in the pathogenesis of achalasia and other esophageal motility disorders. 


\section{Intramucosal Dissection of the Esophagus}

Acute intramucosal esophageal dissection is an uncommon complication of EoE $[121,122]$. Acute intramucosal dissection consists of the separation of mucosa and/ or submucosa from deeper muscular layers, resulting in the development of a false lumen $[121,122]$. The risk of intramucosal dissection of the esophagus is increased in iatrogenic cases due to fragility of the esophageal mucosa, including routine endoscopy or endoscopic manipulation with air insufflation, mucosal trauma during foreign body ingestion, and inflammatory conditions, such as EoE $[121,123]$.

\section{Hepatic Portal Venous Gas}

Hepatic portal venous gas is an uncommon condition in which intraluminal gas or gas produced by bacteria in the gastrointestinal tract enters the portal venous circulation. It is often related to significant underlying pathologies such as intestinal ischemia, sepsis, inflammatory bowel diseases, bowel obstruction, diverticulitis, appendicitis, and trauma. Rarely, hepatic portal venous gas after an upper gastrointestinal endoscopy and dilation for benign esophageal strictures with EoE has also been reported in few studies [124, 125].

\section{Adrenal Insufficiency}

It is a condition of inadequate production of steroid hormones by adrenal glands, mainly cortisol; however, the aldosterone production can also be impaired. Recently, a children-based study reported $5 \%$ of cases of EoE, who were treated with topical corticosteroids, presented with adrenal insufficiency [126]. However, more data and research work are required to assess the efficacy of screening adrenal insufficiency in patients with EoE.

\section{Conclusions}

EoE is recently a more frequently occurring condition characterized by chronic inflammation and strictures. The etiology of EoE is multifactorial and most frequently occurs in patients with certain risk factors such as inflammatory mediators, genetic susceptibility, environmental factors, atopic conditions, and dietary products. Esophageal involvement with eosinophils may be manifested as isolated or with coexisting conditions and should be taken into consideration in the differential diagnosis. There could be a number of other contributing factors that can lead to EoE. Therefore, significant research studies are necessary to better understand the etiopathogenesis of

EoE and its relationship with coexisting and correlated diseases.

\section{Disclosure Statement}

The authors have no conflicts of interest to declare.

\section{Funding Sources}

This study was supported by Science and Technology Plan Project of Tianjin (17ZXMFSY00210).

\section{Author Contributions}

S.K. contributed to the paper in writing, data collection, and manuscript preparation. G.X. was involved in clinical studies. T.L. and M.Q. were involved in endoscopic imaging and literature search. K.J. contributed to the definition of intellectual content, data acquisition, and structural format. L.P.Z. performed review. B.M.W. and X.C. contributed to the study concept, design, manuscript editing, and manuscript review. All authors read and approved the final manuscript.

\section{Geolocation Information} China

This study was carried out in Tianjin City, People's Republic of

References

Digestion 2021;102:342-356

DOI: $10.1159 / 000508191$
1 Mudde ACA, Lexmond WS, Blumberg RS, Nurko S, Fiebiger E. Eosinophilic esophagitis: published evidences for disease subtypes, indications for patient subpopulations, and how to translate patient observations to murine experimental models. World Allergy Organ J. 2016;9:23.

2 Guarino MP, Cicala M, Behar J. Eosinophilic esophagitis: new insights in pathogenesis and therapy. World J Gastrointest Pharmacol Therapeut. 2016;7(1):66-77.

3 Choudhury S, Baker S. Eosinophilic esophagitis: the potential role of biologics in its treatment. Clin Rev Allergy Immunol. 2019.

4 Gisasola P, Iriarte A, Larez MR, Casanova L, Bujanda L. Mediastinal abscess, an unusual way of presentation of eosinophilic esophagitis. Allergy Asthma Clin Immunol. 2019; 15:12.

5 Andreae DA, Hanna MG, Magid MS, Malerba S, Andreae MH, Bagiella E, et al. Swallowed fluticasone propionate is an effective longterm maintenance therapy for children with eosinophilic esophagitis. Am J Gastroenterol. 2016;111(8):1187-97. 
6 González-Cervera J, Lucendo AJ. Eosinophilic esophagitis: an evidence-based approach to therapy. J Investig Allergol Clin Immunol. 2016;26(1):8-18.

7 Furuta GT, Katzka DA. Eosinophilic esophagitis. N Engl J Med. 2015;373(17):1640-8.

8 Richter JE. Current management of eosinophilic esophagitis 2015. J Clin Gastroenterol. 2016;50(2):99-110.

9 Soylu A, Altintas A, Cakmak S, Poturoglu S, Kaya H, Sevindir I, et al. The coexistence of eosinophilic esophagitis with allergic rhinitis. Eur Rev Med Pharmacol Sci. 2016;20(11): 2315-23.

10 Teoh T, Chan ES, Avinashi V, Ko HH, Goldman RD. Diagnosis and management of eosinophilic esophagitis in children. Can Fam Physician. 2015;61(8):687-90.

11 Lyles J, Rothenberg M. Role of genetics, environment, and their interactions in the pathogenesis of eosinophilic esophagitis. Curr Opin Immunol. 2019;60:46-53.

12 Leung J, Beukema KR, Shen AH. Allergic mechanisms of eosinophilic oesophagitis. Best Pract Res Clin Gastroenterol. 2015 29(5):709-20.

13 Jung DH, Yun GW, Lee YJ, Jo Y, Park H. Clinicopathologic analysis of proton pump inhibitor-responsive esophageal eosinophilia in Korean patients. Gut Liver. 2016;10(1):37-41.

14 Nguyen N, Furuta GT, Menard-Katcher C. Recognition and assessment of eosinophilic esophagitis: the development of new clinical outcome metrics. Gastroenterol Hepatol. 2015;11(10):670-4.

15 Cheng E, Zhang X, Wilson KS, Wang DH, Park JY, Huo X, et al. JAK-STAT6 pathway inhibitors block eotaxin-3 secretion by epithelial cells and fibroblasts from esophageal eosinophilia patients: promising agents to improve inflammation and prevent fibrosis in EoE. PloS One. 2016;11(6):e0157376.

16 Shoda T, Morita H, Nomura I, Ishimura N Ishihara S, Matsuda A, et al. Comparison of gene expression profiles in eosinophilic esophagitis (EoE) between Japan and Western countries. Allergol Int. 2015;64(3):260-5.

17 Surdea-Blaga T, David L, Botan EC, Dumitrascu DL. Achalasia-like changes in eosinophilic esophagitis. J Gastrointest Liver Dis. 2019;28:146.

18 Sayej WN, Ménoret A, Maharjan AS, Fernandez M, Wang Z, Balarezo F, et al. Characterizing the inflammatory response in esophageal mucosal biopsies in children with eosinophilic esophagitis. Clin Transl Immunology. 2016;5(7):e88

19 Savarino EV, Tolone S, Bartolo O, de Cassan C, Caccaro R, Galeazzi F, et al. The GerdQ questionnaire and high resolution manometry support the hypothesis that proton pump inhibitor-responsive oesophageal eosinophilia is a GERD-related phenomenon. Aliment Pharmacol Ther. 2016;44(5):522-30.
20 Capucilli P, Hill DA. Allergic comorbidity in eosinophilic esophagitis: mechanistic relevance and clinical implications. Clin Rev Allergy Immunol. 2019;57(1):111-27.

21 Hruz P, Straumann A, Bussmann C, Heer P, Simon HU, Zwahlen M, et al. Escalating incidence of eosinophilic esophagitis: a 20 -year prospective, population-based study in Olten County, Switzerland. J Allergy Clin Immunol. 2011;128(6):1349-50.e5.

22 Arias Á, Lucendo AJ. Prevalence of eosinophilic oesophagitis in adult patients in a central region of Spain. Eur J Gastroenterol Hepatol. 2013;25(2):208-12.

23 Spergel JM, Book WM, Mays E, Song L, Shah SS, Talley NJ, et al. Variation in prevalence, diagnostic criteria, and initial management options for eosinophilic gastrointestinal diseases in the United States. J Pediatr Gastroenterol Nutr. 2011;52(3):300-6.

24 Ahmed M. Eosinophilic esophagitis in adults: an update. World J Gastrointest Pharmacol Therapeut. 2016;7(2):207-13.

25 Gomez Torrijos E, Gonzalez-Mendiola R, Alvarado M, Avila R, Prieto-Garcia A, Valbuena T, et al. Eosinophilic esophagitis: review and update. Front Med. 2018;5:247.

26 Ridolo E, Martignago I, Pellicelli I, Incorvaia C. Assessing the risk factors for refractory eosinophilic esophagitis in children and adults. Gastroenterol Res Pract. 2019;2019:1-9.

27 Gentile N, Katzka D, Ravi K, Trenkner S, Enders F, Killian J, et al. Oesophageal narrowing is common and frequently under-appreciated at endoscopy in patients with oesophageal eosinophilia. Aliment Pharmacol Ther. 2014;40(11-12):1333-40.

28 D’Alessandro A, Esposito D, Pesce M, Cuomo R, De Palma GD, Sarnelli G. Eosinophilic esophagitis: from pathophysiology to treatment. World J Gastrointest Pathophysiol. 2015;6(4):150-8.

29 Rothenberg ME. Molecular, genetic, and cellular bases for treating eosinophilic esophagitis. Gastroenterology. 2015;148(6):1143-57.

30 Min SB, Nylund CM, Baker TP, Ally M, Reinhardt B, Chen YJ, et al. Longitudinal evaluation of noninvasive biomarkers for eosinophilic esophagitis. J Clin Gastroenterol. 2016; 51(2):127-35

31 Dellon ES, Speck O, Woodward K, Covey S, Rusin S, Gebhart JH, et al. Markers of eosinophilic inflammation for diagnosis of eosinophilic esophagitis and proton pump inhibitor-responsive esophageal eosinophilia: a prospective study. Clin Gastroenterol Hepatol. 2014;12(12):2015-22.

32 Jiang M, Ku WY, Zhou Z, Dellon ES, Falk GW, Nakagawa H, et al. BMP-driven NRF2 activation in esophageal basal cell differentiation and eosinophilic esophagitis. J Clin Invest. 2015;125(4):1557-68.

33 Lucendo AJ. Cellular and molecular immunological mechanisms in eosinophilic esophagitis: an updated overview of their clinical implications. Expert Rev Gastroenterol Hepatol. 2014;8(6):669-85.
34 Rawson R, Yang T, Newbury RO, Aquino M, Doshi A, Bell B, et al. TGF- $\beta 1$-induced PAI-1 contributes to a profibrotic network in patients with eosinophilic esophagitis. J Allergy Clin Immunol. 2016;138(3):791-800.e4.

35 Tkachenko E, Rawson R, La E, Doherty TA, Baum R, Cavagnero K, et al. Rigid substrate induces esophageal smooth muscle hypertrophy and eosinophilic esophagitis fibrotic gene expression. J Allergy Clin Immunol. 2016; 137(4):1270-2.e1.

36 Niranjan R, Rajavelu P, Ventateshaiah SU, Shukla JS, Zaidi A, Mariswamy SJ, et al. Involvement of interleukin-18 in the pathogenesis of human eosinophilic esophagitis. Clin Immunol. 2015;157(2):103-13.

37 Arias Á, Lucendo AJ, Martínez-Fernández P, González-Castro AM, Fortea M, GonzálezCervera J, et al. Dietary treatment modulates mast cell phenotype, density, and activity in adult eosinophilic oesophagitis. Clin Exp Allergy. 2016;46(1):78-91.

38 Iwakura N, Fujiwara Y, Tanaka F, Tanigawa $\mathrm{T}$, Yamagami H, Shiba M, et al. Basophil infiltration in eosinophilic oesophagitis and proton pump inhibitor-responsive oesophageal eosinophilia. Aliment Pharmacol Ther. 2015. 41(8):776-84.

39 Merves J, Chandramouleeswaran PM, Benitez AJ, Muir AB, Lee AJ, Lim DM, et al. Altered esophageal histamine receptor expression in eosinophilic esophagitis (EoE): implications on disease pathogenesis. PloS One. 2015; 10(2):e0114831.

40 García-Rojo M, Sánchez J, de la Santa E, Durán E, Ruiz JL, Silva A, et al. Automated image analysis in the study of lymphocyte subpopulation in eosinophilic oesophagitis. Diagn Pathol. 2014;9(Suppl 1):S7.

41 Dellon ES, Gonsalves N, Hirano I, Furuta GT, Liacouras CA, Katzka DA. ACG clinical guideline: evidenced based approach to the diagnosis and management of esophageal eosinophilia and eosinophilic esophagitis (EoE). Am J Gastroenterol. 2013;108(5):679-93.

42 Gambichler T, Kröger ES, Tannapfel A, Dörler M, Susok L. Hypereosinophilic syndrome complicated by severe vascular damage and gangrene. J Vasc Surg Cases Innov Tech. 2019;5(3):384-7.

43 Spechler SJ. Eosinophilic esophagitis: novel concepts regarding pathogenesis and clinical manifestations. J Gastroenterol. 2019;54(10): 837-44.

44 Cianferoni A. Wheat allergy: diagnosis and management. J Asthma Allergy. 2016;9:1325.

45 Arasi S, Costa S, Magazzù G, Ieni A, Crisafulli G, Caminiti L, et al. Omalizumab therapy in a 13-year-old boy with severe persistent asthma and concomitant eosinophilic esophagitis. Ital J Pediatr. 2016;42:32.

Khan/Guo/Liu/Iqbal/Jiang/Zhu/Chen/ Wang 
46 Judd LM, Heine RG, Menheniott TR, Buzzelli J, O'Brien-Simpson N, Pavlic D, et al. Elevated IL-33 expression is associated with pediatric eosinophilic esophagitis, and exogenous IL-33 promotes eosinophilic esophagitis development in mice. Am J Physiol Gastrointest Liver Physiol. 2015;310(1):G13-25.

47 Sleiman PM, Wang ML, Cianferoni A, Aceves S, Gonsalves N, Nadeau K, et al. GWAS identifies four novel eosinophilic esophagitis loci. Nat Commun. 2014;5:5593.

48 Krishnamurthy P, Kaplan MH. STAT6 and PARP family members in the development of $T$ cell-dependent allergic inflammation. Immune Netw. 2016;16(4):201-10.

49 Moawad FJ, Wells JM, Johnson RL, Reinhardt BJ, Maydonovitch CL, Baker TP. Comparison of eotaxin-3 biomarker in patients with eosinophilic oesophagitis, proton pump inhibitor-responsive oesophageal eosinophilia and gastro-oesophageal reflux disease. Aliment Pharmacol Ther. 2015;42(2):231-8.

50 Aceves SS. Unmet therapeutic needs in eosinophilic esophagitis. Dig Dis. 2014;32(12):143-8.

51 Collins MH. Histopathology of eosinophilic esophagitis. Dig Dis. 2014;32(1-2):68-73.

52 Alexander ES, Martin LJ, Collins MH, Kottyan LC, Sucharew H, He H, et al. Twin and family studies reveal strong environmental and weaker genetic cues explaining heritability of eosinophilic esophagitis. J Allergy Clin Immunol. 2014;134(5):1084-92.e1.

53 Kottyan LC, Davis BP, Sherrill JD, Liu K, Rochman M, Kaufman K, et al. Genome-wide association analysis of eosinophilic esophagitis provides insight into the tissue specificity of this allergic disease. Nat Genet. 2014; 46(8):895-900.

54 Litosh VA, Rochman M, Rymer JK, Porollo A, Kottyan LC, Rothenberg ME. Calpain-14 and its association with eosinophilic esophagitis. J Allergy Clin Immunol. 2017;139(6):1762-71. e7.

55 Jensen ET, Shah ND, Hoffman K, Sonnenberg A, Genta RM, Dellon ES. Seasonal variation in detection of oesophageal eosinophilia and eosinophilic oesophagitis. Aliment Pharmacol Ther. 2015;42(4):461-9.

56 Jensen ET, Dellon ES. Environmental factors and eosinophilic esophagitis. J Allergy Clin Immunol. 2018;142(1):32-40.

57 Moawad FJ, Veerappan GR, Lake JM, Maydonovitch CL, Haymore BR, Kosisky SE, et al. Correlation between eosinophilic oesophagitis and aeroallergens. Aliment Pharmacol Ther. 2010;31(4):509-15.

58 Sorser SA, Barawi M, Hagglund K, Almojaned M, Lyons H. Eosinophilic esophagitis in children and adolescents: epidemiology, clinical presentation and seasonal variation. Gastroenterol. 2013;48(1):81-5.

59 Elitsur Y, Aswani R, Lund V, Dementieva Y. Seasonal distribution and eosinophilic esophagitis: the experience in children living in rural communities. J Clin Gastroenterol. 2013; $47(3): 287-8$.
60 van Rhijn BD, Verheij J, Smout AJ, Bredenoord AJ. Rapidly increasing incidence of eosinophilic esophagitis in a large cohort. Neurogastroenterol Motil. 2013;25(1):47-52.e5.

61 Fahey L, Robinson G, Weinberger K, Giambrone AE, Solomon AB. Correlation between aeroallergen levels and new diagnosis of eosinophilic esophagitis in New York City. J Pediatr Gastroenterol Nutr. 2017;64(1):22-5.

62 Ridolo E, Melli V, De'Angelis G, Martignago I. Eosinophilic disorders of the gastro-intestinal tract: an update. Clin Mol Allergy. 2016; 14:17.

63 von Arnim U, Wex T, Link A, Messerschmidt M, Venerito M, Miehlke S, et al. Helicobacter pylori infection is associated with a reduced risk of developing eosinophilic oesophagitis. Aliment Pharmacol Ther. 2016;43(7):825-30.

64 Benninger MS, Strohl M, Holy CE, Hanick AL, Bryson PC. Prevalence of atopic disease in patients with eosinophilic esophagitis. Int Forum Allergy Rhinol. 2017;7(8):757-62.

65 van Rhijn BD, Vlieg-Boerstra BJ, Versteeg SA, Akkerdaas JH, van Ree R, Terreehorst I, et al. Evaluation of allergen-microarray-guided dietary intervention as treatment of eosinophilic esophagitis. J Allergy Clin Immunol. 2015; 136(4):1095-7.e3.

66 Capucilli P, Cianferoni A, Grundmeier RW, Spergel JM. Comparison of comorbid diagnoses in children with and without eosinophilic esophagitis in a large population. Ann Allergy Asthma Immunol. 2018;121(6):711-6

67 Spechler SJ. Histologic features of gastroesophageal reflux disease and eosinophilic esophagitis. Gastroenterol Hepatol. 2019;8(7): 472-3.

68 Molina-Infante J, Arias A, Barrio J, Rodríguez-Sánchez J, Sanchez-Cazalilla M, Lucendo AJ. Four-food group elimination diet for adult eosinophilic esophagitis: a prospective multicenter study. J Allergy Clin Immunol. 2014;134(5):1093-9.e1

69 Teoh T, Mill C, Chan E, Zimmer P, Avinashi V. Liberalized versus strict cow's milk elimination for the treatment of children with eosinophilic esophagitis. J Can Assoc Gastroenterol. 2019;2(2):81-5.

70 Human Microbiome Project Consortium. Structure, function and diversity of the healthy human microbiome. Nature. 2012; 486(7402):207-14.

71 Harris JK, Fang R, Wagner BD, Choe HN, Kelly CJ, Schroeder S, et al. Esophageal microbiome in eosinophilic esophagitis. PloS One. 2015;10(5):e0128346.

72 Hiremath G, Shilts MH, Boone HH, Correa $\mathrm{H}$, Acra S, Tovchigrechko A, et al. The salivary microbiome is altered in children with eosinophilic esophagitis and correlates with disease activity. Clin Transl Gastroenterol. 2019;10(6):e00039.

73 Benitez AJ, Hoffmann C, Muir AB, Dods KK, Spergel JM, Bushman FD, et al. Inflammation-associated microbiota in pediatric eosinophilic esophagitis. Microbiome. 2015;3:23.
74 Lucendo AJ, Arias A, Tenias JM. Relation between eosinophilic esophagitis and oral immunotherapy for food allergy: a systematic review with meta-analysis. Ann Allergy Asthma Immunol. 2014;113(6):624-9.

75 Hill DA, Dudley JW, Spergel JM. The prevalence of eosinophilic esophagitis in pediatric patients with IgE-mediated food allergy. J Allergy Clin Immunol Pract. 2017;5(2):369-75.

76 Gómez Torrijos E, Mendez Díaz Y, Moreno Lozano L, Extremera Ortega AM, Borja Segade J, Feo Brito JF, et al. Frequency and course of eosinophilic esophagitis during oral immunotherapy for cow's milk allergy in a series of 57 children. J Investig Allergol Clin Immunol. 2017;27(2):132-3.

77 Hill DA, Grundmeier RW, Ramos M, Spergel JM. Eosinophilic esophagitis is a late manifestation of the allergic march. J Allergy Clin Immunol Pract. 2018;6(5):1528-33.

78 Dellon ES. The esophageal microbiome in eosinophilic esophagitis. Gastroenterology. 2016;151(2):364-5.

79 Takashima S, Tanaka F, Otani K, Hosomi S, Nagami Y, Kamata N, et al. Barrett's esophagus is negatively associated with eosinophilic esophagitis in Japanese subjects. Esophagus. 2019;16(2):168-73.

80 Dellon ES, Peery AF, Shaheen NJ, Morgan DR, Hurrell JM, Lash RH, et al. Inverse association of esophageal eosinophilia with Helicobacter pylori based on analysis of a US pathology database. Gastroenterology. 2011; 141(5):1586-92.

81 Molina-Infante J, Gutierrez-Junquera C, Savarino E, Penagini R, Modolell I, Bartolo O, et al. Helicobacter pylori infection does not protect against eosinophilic esophagitis: results from a large multicenter case-control study. Am J Gastroenterol. 2018;113(7):972-9.

82 Kia L, Hirano I. Distinguishing GERD from eosinophilic oesophagitis: concepts and controversies. Nat Rev Gastroenterol Hepatol. 2015;12(7):379-86

83 Zukerberg L, Mahadevan K, Selig M, Deshpande V. Oesophageal intrasquamous IgG4 deposits: an adjunctive marker to distinguish eosinophilic oesophagitis from reflux oesophagitis. Histopathology. 2016;68(7):96876.

84 Hui Y, Chen S, Lombardo KA, Resnick MB, Mangray S, Matoso A. ALOX15 immunohistochemistry aids in the diagnosis of eosinophilic esophagitis on pauci-eosinophilic biopsies in children. Pediatr Dev Pathol. 2016; 20(5):375-80.

85 von Arnim U, Röhl FW, Miehlke S, Jechorek D, Reinhold D, Wex T, et al. Clinical symptom tool that raises the index of suspicion for eosinophilic oesophagitis in adults and drives earlier biopsy for definitive diagnosis. Aliment Pharmacol Ther. 2017;45(3):417-26.

86 Talathi S, Knight T, Dimmitt R, Mestre J, Jester T. Concurrent eosinophilic esophagitis in pediatric patients with inflammatory bowel disease: a case series. Ann Allergy Asthma Immunol. 2019;123(3):313-6. 
87 Limketkai BN, Shah SC, Hirano I, Bellaguarda E, Colombel JF. Epidemiology and implications of concurrent diagnosis of eosinophilic oesophagitis and IBD based on a prospective population-based analysis. Gut. 2019; 68(12):2152-60.

88 Hommeida S, Alsawas M, Murad MH, Katzka DA, Grothe RM, Absah I. The association between celiac disease and eosinophilic esophagitis: mayo experience and meta-analysis of the literature. J Pediatr Gastroenterol Nutr. 2017;65(1):58-63.

89 Wallach T, Genta RM, Lebwohl B, Green PHR, Reilly NR. Adherence to celiac disease and eosinophilic esophagitis biopsy guidelines is poor in children. J Pediatr Gastroenterol Nutr. 2017;65(1):64-8.

90 Patton T, Chugh A, Padhye L, DeGeeter C, Guandalini S. Pediatric celiac disease and eosinophilic esophagitis: outcome of dietary therapy. J Pediatr Gastroenterol Nutr. 2019; 69(2):e43.

91 Vaz AM, Cadilla AJ, Sousa D, Guerreiro H. Eosinophilic oesophagitis and coeliac disease: is there an association? BMJ Case Rep. 2017; 2017:bcr-2017.

92 Ari A, Morgenstern S, Chodick G, Matar M, Silbermintz A, Assa A, et al. Oesophageal eosinophilia in children with coeliac disease. Arch Dis Child. 2017;102(9):825-9.

93 Truskaite K, Dlugosz A. Prevalence of eosinophilic esophagitis and lymphocytic esophagitis in adults with esophageal food bolus impaction. Gastroenterol Res Pract. 2016; 2016:1-6.

94 Rubio CA, Ichiya T, Schmidt PT. Lymphocytic oesophagitis, eosinophilic oesophagitis and compound lymphocytic-eosinophilic oesophagitis I: histological and immunohistochemical findings. J Clin Pathol. 2017; 70(3):208-16.

95 Tanaka S, Sakai A, Masuda A, Ashina S, Yamakawa K, Tsujimae M, et al. Eosinophilic cholangitis without biliary stricture after the treatment of eosinophilic esophagitis. ACG Case Rep J. 2019;6(6):e00099-3.

96 Corder SR, Weston BW, Dellon ES. Rare cooccurrence of eosinophilic esophagitis and type $2 \mathrm{~B}$ von Willebrand disease: implications for endoscopic surveillance and esophageal dilation. ACG Case Rep J. 2019;6(5):e000694.

97 Scaffidi MA, Garg A, Ro B, Wang C, Yang TTC, Plener IS, et al. Esophageal intramural pseudodiverticulosis and concomitant eosinophilic esophagitis: a case series. Can J Gastroenterol Hepatol. 2016;2016:1761874.

98 Kathi PR, Tama M, Thammineni N, Ehrinpreis M. Pseudodiverticulosis: a rare presentation of eosinophilic esophagitis. Clin J Gastroenterol. 2019:13(2):170-2.

99 Mahjoub FE, Fallahi GH, Niknejad N. Vascular changes in eosinophilic esophagitis (EOE), report of an unusual case. Fetal Pediatr Pathol. 2019:1-6.
100 Frech TM, Boynton K, Downs-Kelly E, Jones B, Kriesel JD, Peterson K. Eosinophilic esophagitis in two patients with systemic sclerosis. Case Rep Rheumatol. 2016; 2016:1-5.

101 Clayton F, Fang JC, Gleich GJ, Lucendo AJ, Olalla JM, Vinson LA, et al. Eosinophilic esophagitis in adults is associated with IgG4 and not mediated by IgE. Gastroenterology. 2014;147(3):602-9.

102 Simon D, Cianferoni A, Spergel JM, Aceves S, Holbreich M, Venter C, et al. Eosinophilic esophagitis is characterized by a non-IgEmediated food hypersensitivity. Allergy. 2016;71(5):611-20.

103 Chehade M, Sher E. Medical therapy versus dietary avoidance in eosinophilic esophagitis: which approach is better? Allergy Asthma Proc. 2017;38(3):170-6.

104 Khan S, Zhu LP, Jiang K, Liu W, Chen X, Wang BM. Immunoglobulin G4-related disease manifesting as isolated, typical, and nontypical gastroesophageal lesion: a research of literature review. Digestion. 2019; $1-16$.

105 Wright B, Kulis M, Guo R, Orgel K, Wolf W, Burks A, et al. Food-specific IgG4 is associated with eosinophilic esophagitis. J Allergy Clin Immunol. 2016;138(4):1190-2.e3.

106 Fritz J, Lerner D, Suchi M. Herpes simplex virus esophagitis in immunocompetent children: a harbinger of eosinophilic esophagitis? J Pediatr Gastroenterol Nutr. 2018; 66(4):609-13.

107 Iriarte Rodriguez A, Frago Marquinez I, de Lima Pina GP. A case report: asymptomatic esophageal eosinophilia after herpes simplex esophagitis. Controversies in the therapeutic approach. Rev Esp Enferm Dig. 2018; 110(7):471-2.

108 Zimmermann D, Criblez DH, Dellon ES, Bussmann C, Pfeifer D, Froh M, et al. Acute herpes simplex viral esophagitis occurring in 5 immunocompetent individuals with eosinophilic esophagitis. ACG Case Rep J. 2016;3(3):165-8.

109 Kim J, Lee K, Lee W. A case of eosinophilic esophagitis associated with herpes esophagitis in a pediatric patient. Korean J Gastrointest Endosc. 2019;52(6):606-11.

110 Guerra M-AR, Vahabnezhad E, Swanson E Naini BV, Wozniak LJ. Esophagitis dissecans associated with eosinophilic esophagitis in an adolescent. Adv Pediatr Res. 2015; 2(8).

111 Ahlawat R, Parikh NS, Jhaveri A. Triple diagnosis of Crohn's disease, celiac disease, and eosinophilic esophagitis in a child with Siderius-Hamel syndrome. WMJ. 2019; 118(3):140-2.

112 Šaban J, Milošević V. A rare case of eosinophilic esophagitis and eosinophilic subserosal gastroenteritis with ascites. Turk J Gastroenterol. 2019;30(9):851-3.
113 Syed A, Maradey-Romero C, Fass R. The relationship between eosinophilic esophagitis and esophageal cancer. Dis Esophagus. 2017;30(7):1-5

114 Issa D, Alwatari Y, Smallfield GB, Shah RD. Spontaneous transmural perforation in eosinophilic esophagitis: RARE case presentation and role of esophageal stenting. J Surg Case Rep. 2019;2019(6):rjz190.

115 Lucendo AJ, Friginal-Ruiz AB, Rodriguez B. Boerhaave's syndrome as the primary manifestation of adult eosinophilic esophagitis. Two case reports and a review of the literature. Dis Esophagus. 2011;24(2):E11-15.

116 Vernon N, Mohananey D, Ghetmiri E, Ghaffari G. Esophageal rupture as a primary manifestation in eosinophilic esophagitis. Case Rep Med. 2014;2014:1-5.

117 Nurko S, Rosen R. Esophageal dysmotility in patients who have eosinophilic esophagitis. Gastrointest Endosc Clin. 2008;18(1):73-89.

118 Martin Martin L, Santander C, Lopez Martin MC, Espinoza-Rios J, Chavarria-Herbozo C, Gisbert JP, et al. Esophageal motor abnormalities in eosinophilic esophagitis identified by high-resolution manometry. J Gastroenterol Hepatol. 2011;26(9):1447-50.

119 Jon Spechler S, Konda V, Souza R. Can eosinophilic esophagitis cause achalasia and other esophageal motility disorders? Am J Gastroenterol. 2018;113:1594-9.

120 Landres RT, Kuster GG, Strum WB. Eosinophilic esophagitis in a patient with vigorous achalasia. Gastroenterology. 1978;74(6): 1298-301.

121 Fianchi F, De Matteis G, Cianci R, Pizzoferrato $\mathrm{M}$, Cardone $\mathrm{S}$, Nicolazzi MA, et al. Acute intramucosal dissection in eosinophilic esophagitis. Clin J Gastroenterol. 2019;12:525-9.

122 Sgro A, Betalli P, Battaglia G, Bardini R, Crivellaro MA, Svaluto G, et al. An unusual complication of eosinophilic esophagitis in an adolescent: intramural esophageal dissection. Endoscopy. 2012;44(Suppl 2):E419420.

123 Predina JD, Anolik RB, Judy B, Akers S, Freiman D, Ahmad N, et al. Intramural esophageal dissection in a young man with eosinophilic esophagitis. Ann Thorac Cardiovasc Surg. 2012;18(1):31-5.

124 Seeger K, Achem SR. Hepatic portal venous gas: an unusual complication following upper endoscopy and dilation. ACG Case Rep J. 2014;1(3):128-30.

125 Okada S, Azuma T, Kawashita Y, Matsuo S, Eguchi S. Clinical evaluation of hepatic portal venous gas after abdominal surgery. Case Rep Gastroenterol. 2016;10(1):103-12.

126 Bose P, Kumar S, Nebesio TD, Li C, Hon EC, Atkins D, et al. Adrenal insufficiency in children with eosinophilic esophagitis treated with topical corticosteroids. J Pediatr Gastroenterol Nutr. 2019;70:324-9. 